\title{
Analisis Fraktal Citra Mammogram Berbasis Tekstur Sebagai Pendukung Diagnosis Kanker Payudara
}

\author{
Muspika Helja ${ }^{1)}$, Nurhasanah ${ }^{1)}$, Joko Sampurno1) \\ 1) Program Studi Fisika, Fakultas Matematika dan Ilmu Pengetahuan Alam \\ Universitas Tanjungpura \\ e-mail : pika_helja@yahoo.co.id
}

\begin{abstract}
Abstrak
Penelitian ini mengkaji tentang analisa citra mammogram dengan menggunakan metode analisis fraktal. Pengolahan citra dimulai dengan mengubah citra berwarna menjadi citra grayscale, kemudian dilanjutkan dengan proses thresholding untuk mendapatkan citra biner. Proses selanjutnya adalah hitung dimensi fraktal dari citra biner tersebut dengan metode box counting. Hasil penelitian menentukan bahwa citra mammogram normal memiliki dimensi fraktal antara 1,683 hingga 1,796, citra mammogram tumor jinak memiliki dimensi fraktal antara 1,837 hinggga 1,889, dan citra mammogram kanker (tumor ganas) dengan dimensi fraktal antara 1,907 hingga 1,908. Hasil penelitian ini menunjukkan bahwa dimensi fraktal dapat digunakan untuk membedakan citra mammogram normal dan citra mammogram abnormal (tumor dan kanker).
\end{abstract}

Kata kunci : citra mammogram, dimensi fraktal, box-counting

\section{Pendahuluan}

Analisa citra radiologi dalam bidang kedokteran semakin banyak digunakan karena dalam proses diagnosanya tidak membutuhkan pembedahan, tetapi hanya mengandalkan citra organ internal tubuh seperti citra mamografi. Mamografi merupakan suatu metode pemeriksaan yang menggunakan sinar-x dosis rendah untuk mendeteksi dini keberadaan jaringan abnormal pada payudara. Pembacaan mammogram membutuhkan tingkat akurasi tinggi dalam proses diagnosa kanker payudara, karena apabila terjadi suatu kesalahan dalam membaca hasil ini akan berakibat fatal. Selain itu, seringkali seorang dokter tidak dapat secara langsung membaca film (mammogram) dari hasil pemeriksaan mamografi, sehingga diperlukan waktu yang cukup lama untuk pasien mengetahui hasil dari pemeriksaan tersebut.

Untuk penelitian tentang analisa hasil pemeriksaan mamografi telah banyak dilakukan seperti Indrati dan Madenda (2009) dalam penelitiannya mengenai Ekstraksi Fitur Bentuk Tumor Payudara dengan menggunakan Region of Interest (ROI), edge detection (deteksi tepi objek), dan penipisan tepi objek (countour delimitation) tumor payudara. Pada penelitiannya didapatkan tepi tumor yang lebih jelas, namun tepi tersebut bukan merupakan tepi yang sebenarnya, karena masih terdapat efek noise dan blur yang akan berpengaruh pada proses ROI. Selanjutnya Nurhayati dkk (2010) dengan penelitiannya mengenai Ekstraksi Ciri Citra Termogram Payudara Berbasis Dimensi Fraktal, menggunakan metode deteksi tepi canny, dan dimensi hausdorff, yang digunakan untuk mengekstrak ciri yang terdapat pada citra termogram.

Penelitian ini memanfaatkan metode analisis fraktal untuk membedakan antara citra mammogram dengan jaringan yang sehat dan jaringan yang abnormal (tumor dan kanker). Karena dengan analisis fraktal dapat mendeskripsikan tekstur yang terdapat pada citra mammogram payudara.

\section{Landasan Teori}

\subsection{Mamografi}

Mamografi merupakan suatu metode pemeriksaan payudara yang menggunakan sinar-X dengan dosis rendah yang dapat memperlihatkan keabnormalan atau kelainan pada payudara dalam bentuk yang sangat kecil (mikrokalsifikasi) yang pertumbuhannya tidak dapat teraba. Pemeriksaan ini menggunakan bantuan alat yang dinamakan dengan pesawat mamografi. Hasil yang terekam dari pemeriksaan mamografi ini biasa disebut dengan mammogram, seperti yang terlihat pada gambar 1. 


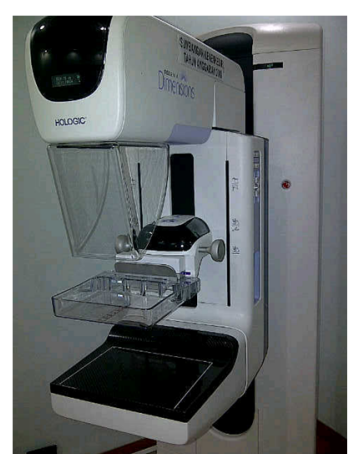

Gambar 1. Pesawat mamografi

\subsection{Fraktal}

Menurut Benoit Mandelbrot pada tahun 1975 dalam bukunya yang berjudul The Fractal Geometry of Nature, kata fraktal berasal dari bahasa latin fractus yang artinya patah, pecah, dan tidak teratur. Fraktal adalah suatu objek yang memiliki kemiripan yang sama dengan dirinya sendiri pada skala yang berbeda, dimana bagian yang lebih kecil pada sebuah objek akan mirip dengan objek tersebut apabila dilihat secara keseluruhan (Putra, 2010).

Karakteristik dari fraktal berbeda dengan geometri Euclidean, dimana karakteristik dari fraktal memiliki dimensi dalam bentuk pecahan, sedangkan geometri Euclidean memiliki dimensi bulat (integer) dari suatu objek. Berdasarkan dua prinsip pada proses penyusunan yaitu keteraturan dan keteracakan terdapat satu prinsip kesamaan diri yang mengarah pada sebuah struktur yang dinamakan dengan fraktal. Ketika bagian dari sebuah sistem pada fraktal ini membesar dengan perbesaran yang sama, sehingga memiliki suatu kemiripan bentuk secara keseluruhan.

Metode Box Counting merupakan salah satu metode yang umumnya telah dikenal untuk menghitung dimensi fraktal suatu citra. Untuk menghitung dimensi dari himpunan $\mathrm{S}$ dalam ruang $\mathrm{R}^{\mathrm{n}}$ atau dalam ruang metrik $(\mathrm{X}, \mathrm{d})$, suatu fraktal diletakkan pada suatu luasan bidang kotak. Selanjutnya dihitung dengan seberapa banyak kotak yang diperlukan untuk menutup seluruh bagian fraktal tersebut. Kemudian untuk menghitung dimensi box counting ini dihitung kembali banyaknya jumlah kotak yang berubah ketika ukuran kotak tersebut diperkecil hingga panjang sisi $\varepsilon$ mendekati 0 . Dengan demikian dimensi box counting dapat didefinisikan sebagai (Sampurno, 2011) :

dengan :

$$
\operatorname{dim}_{\text {box }}(S)=\lim _{\varepsilon \rightarrow 0}\left(\frac{\log N_{\varepsilon}}{\log (1 / \varepsilon)}\right)
$$

$N_{\varepsilon} \quad$ : jumlah kotak yang memiliki panjang sisi $\varepsilon$ yang menutupi daerah sisi fraktal. $\operatorname{dim}_{b o x}(S)$ : dimensi fraktal yang dihitung dengan metode box-counting.

\section{Metodologi}

Tahapan penelitian yang dilakukan untuk menganalisis citra mammogram berbasis tekstur sebagai pendukung diagnosis kanker payudara dengan menggunakan metode boxcounting yaitu :

1) Pengambilan Data

Data yang digunakan dalam penelitian ini adalah citra mammogram digital yang diperoleh dalam bentuk file, dengan format penyimpananjpg.

2) Cropping

Tahapan cropping merupakan suatu proses pemotongan bagian gambar dari suatu objek. Tujuan dari cropping adalah untuk memotong atau mengambil bagian gambar sesuai dengan area tertentu yang diperlukan berdasarkan bentuk payudara.

3) Thresholding

Proses thresholding ini menggunakan metode Otsu untuk memisahkan antara objek dan background pada citra dengan nilai threshold yang dihasilkan berdasarkan dari tingkat keabuan citra tersebut (Cahyaningsih, 2010). Cara kerja dari metode Otsu ini dengan memaksimalkan varians antar kelas yang cocok untuk menganalisa dikriminan kelas secara statistik (Fitriyani, 2012).

4) Metode Box-Counting

Metode ini dilakukan untuk menghitung dimensi dimana suatu fraktal diletakkan pada suatu luasan bidang kotak. Selanjutnya dihitung dengan seberapa banyak kotak yang diperlukan untuk menutup seluruh bagian fraktal tersebut. Kemudian untuk menghitung dimensi box counting ini dihitung kembali banyaknya jumlah kotak yang berubah ketika ukuran kotak tersebut diperkecil hingga panjang sisi $\varepsilon$ mendekati 0 .

5) Hasil dan Analisis

Berdasarkan metode box-counting yang telah digunakan akan diperoleh hasil atau citra keluaran yang selanjutnya dianalisis untuk mengelompokkan dimensi fraktal untuk jaringan yang sehat dan dimensi fraktal untuk jaringan yang sakit (abnormal).

\section{Hasil dan Diskusi}

Hasil dari thresholding atau pengambangan pada penelitian ini dapat dilihat pada Gambar 2. 


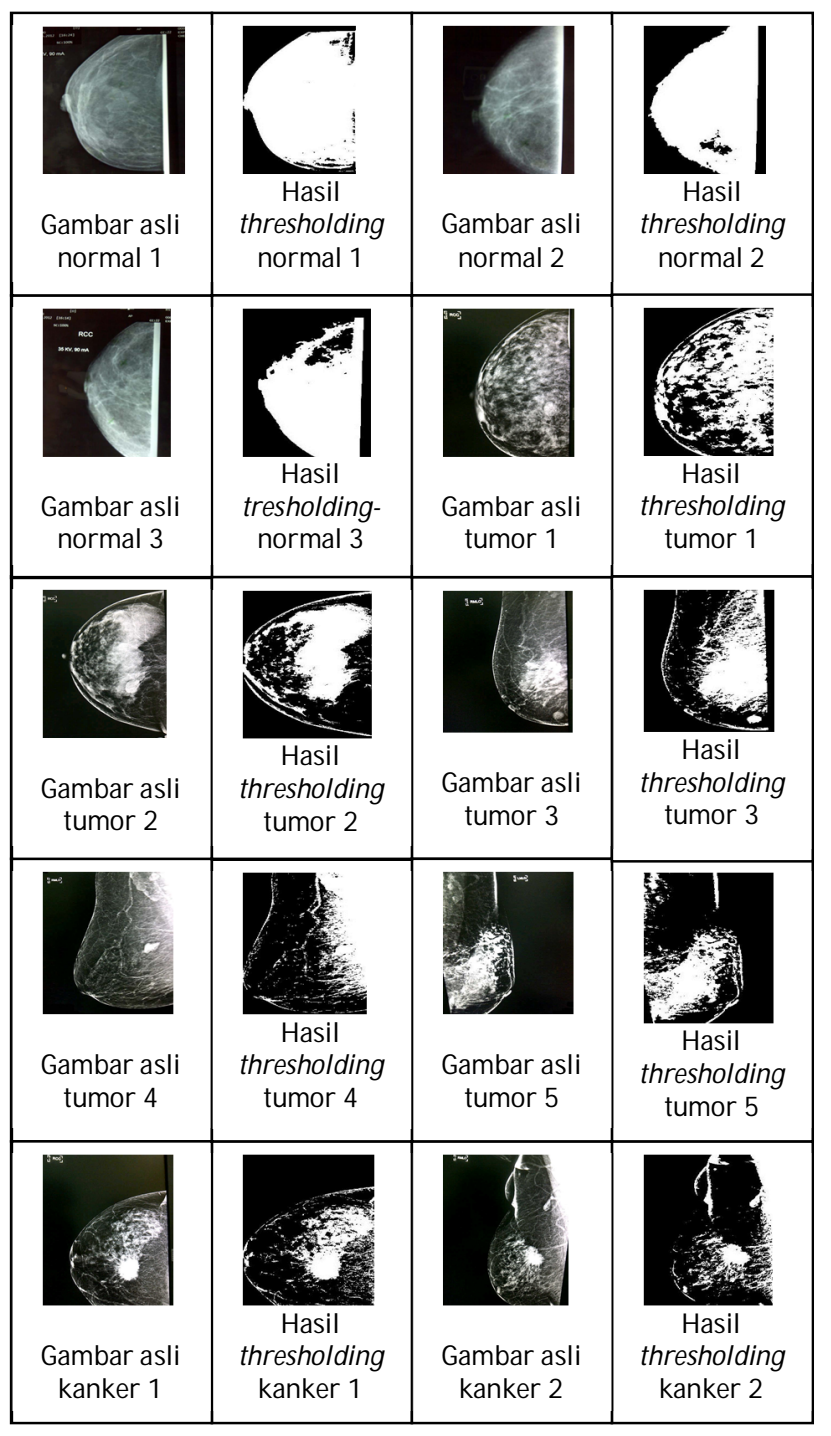

Gambar 2. Citra asli dan citra hasil thresholding

Setelah didapatkan citra biner dari hasil thresholding, maka langkah selanjutnya adalah menghitung nilai dimensi fraktal masing-masing citra dengan metode box counting. Hasil pengolahan data untuk citra mammogram normal diperlihatkan oleh gambar 3.

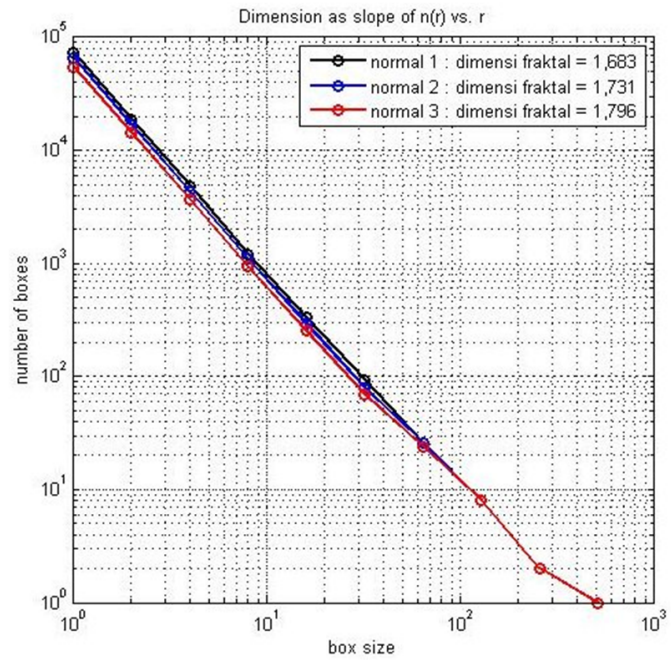

Gambar 3. Grafik dimensi fraktal untuk mammogram normal

Sedangkan hasil pengolahan data untuk citra mammogram tumor jinak dapat dilihat pada gambar 4.

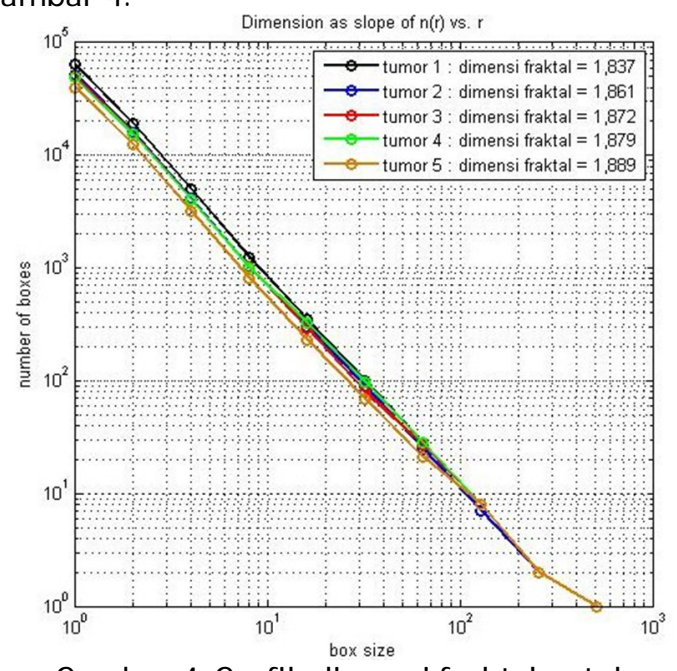

Gambar 4. Grafik dimensi fraktal untuk mammogram tumor

Selain citra mammogram normal dan citra mammogram tumor jinak, diolah juga citra mammogram kanker sebagaimana dilihat pada gambar 5. 


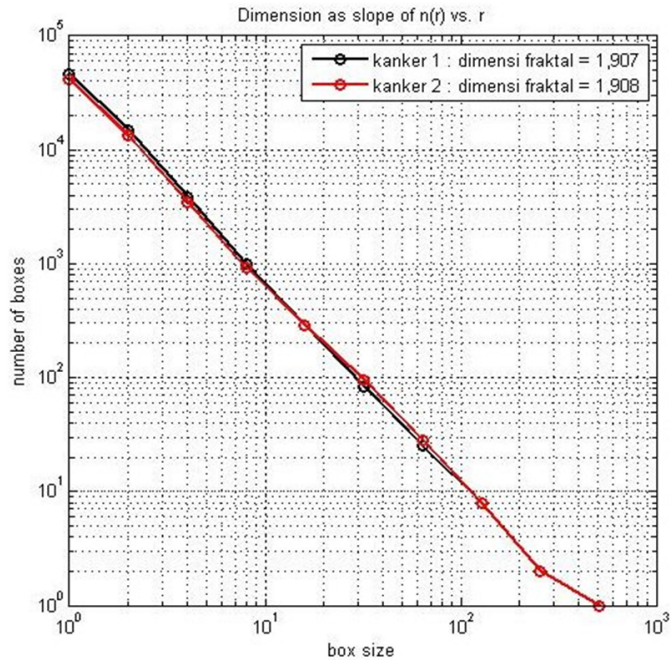

Gambar 5. Grafik dimensi fraktal untuk mammogram kanker

Berdasarkan grafik gambar 3, 4, dan 5 diatas dapat dianalisa bahwa untuk mammogram normal memiliki dimensi fraktal antara 1,683 hingga 1,796, mammogram tumor jinak memiliki dimensi fraktal antara 1,837 hinggga 1,889, dan mammogram kanker (tumor ganas) memiliki dimensi fraktal antara 1,907 hingga 1,908 .

Dimensi fraktal citra mammogram normal lebih rendah dibanding citra mammogram tumor. Sedangkan dimensi fraktal citra mammogram tumor lebih rendah dari dimensi fraktal citra mammogram kanker. Dari data yang diolah, dapat diketahui bahwa citra mammogram normal memiliki nilai dimensi fraktal kurang dari 1,800. Sedangkan citra mammogram abnormal memiliki dimensi fraktal diatas 1,837 .

Nilai dimensi fraktal ini mengkonfirmasi bahwa semakin tinggi dimensi fraktal, maka kepadatan payudaranya semakin tinggi. Sedangkan semakin rendah dimensi fraktalnya, maka kepadatan payudaranya semakin rendah. Hal ini dikarenakan pada mammogram kanker memiliki densitas (kepadatan) yang paling besar dibanding dengan mammogram tumor dan mammogram normal (Nur, 2011).

\section{Kesimpulan}

Berdasarkan hasil penelitian ini dapat disimpulkan bahwa metode analisis fraktal dapat digunakan untuk membedakan antara citra mammogram normal dengan citra mammogram abnormal. Dimensi fraktal citra mammogram normal lebih rendah dari dimensi fraktal tumor, dan dimensi fraktal tumor lebih rendah daripada dimensi fraktal kanker. Untuk citra mammogram normal memiliki dimensi fraktal antara 1,683 hingga 1,796, citra mammogram tumor jinak memiliki dimensi fraktal antara 1,837 hinggga 1,889, dan citra mammogram kanker (tumor ganas) memiliki dimensi fraktal 1,907 hingga 1,908.

\section{Daftar Pustaka}

Cahyaningsih, S., 2010, Deteksi Osteoporosis dengan Thresholding Metode Otsu pada Citra X-Ray Tulang Rahang, Skripsi Program Studi Fisika, Fakultas Sains dan Teknologi, Universitas Islam Negeri Maulana Malik Ibrahim, Malang.

Fitriyani, Y.N., 2012, Aplikasi Deteksi Mikrokalsifikasi dan Klasifikasi Citra Mammogram Berbasis Tekstur Sebagai Pendukung Diagnosis KankerPayudara, Jurnal Program Studi Teknik Informatika, Fakultas Teknologi Industri, Universitas Gunadarma, Depok.

Indrati, A., Madenda S., 2009, Ekstraksi Fitur Bentuk Tumor Payudara, Seminar Nasional Aplikasi Teknologi Informasi 2009, Universitas Gunadarma, Depok.

Nur, I. K., 2011, Distribusi Pasien Kanker Payudara Rawat Inap di RSUP Fatmawati Berdasarkan Jenis Kelamin, Usia, Tingkat Pendidikan dan Tipe Histopatologi Tahun 2008-2009, Skripsi Program Studi Pendidikan Dokter, Fakultas Kedokteran dan Ilmu Kesehatan, Universitas Islam Negeri Syarif Hidayatullah, Jakarta.

Nurhayati, O. D., Thomas S.W., Adhi S., Maesadji T., 2010, Ekstraksi Ciri Citra Termogram Payudara, Jurnal Forum Teknik Vol. 33, No. 2, Mei 2010, Universitas Gadjah Mada, Yogyakarta.

Putra, D. 2010. Pengolahan Citra Digital. Penerbit ANDI : Yogyakarta.

Sampurno, J., 2011, Analisa Fraktal Untuk Karakterisasi Permukaan Daerah Panas Bumi, Tesis S2 Program Studi Fisika, Fakultas MPA, Institut Teknologi Bandung (ITB), Bandung. 
